\title{
A Pilot Study Differentiating Recurrent Major Depression from Bipolar Disorder Cycling on the Depressive Pole [Retraction]
}

Hinz M, Stein A, Uncini T. Neuropsychiatr Dis Treat. 2010;6:741-747.

The Editor-in-chief and Publisher of Neuropsychiatric Disease and Treatment wish to retract the published article.

Following the conclusion of our investigation the decision has been made to retract the published article. The authors did not provide the required IRB and informed consent information relating to this study and it was determined the study did not meet the standard ethical publication requirements for studies involving human subjects in research. These requirements are based on guidelines issued by the World Medical Association and the International Committee of Medical Journal Editors. Additionally, the authors did not provide the required study protocols, raw data and other study documents relating to this study as requested. Given our concerns about the standard of research ethics, competing interests and that the authors have not supplied the information we requested to verify and validate the reported findings, the editor has determined the article should be retracted.

Our decision-making was informed by our policy on publishing ethics and integrity and the COPE guidelines on retraction.

The retracted article will remain online to maintain the scholarly record, but it will be digitally watermarked on each page as "Retracted".

\section{Publish your work in this journal}

Neuropsychiatric Disease and Treatment is an international, peerreviewed journal of clinical therapeutics and pharmacology focusing on concise rapid reporting of clinical or pre-clinical studies on a range of neuropsychiatric and neurological disorders. This journal is indexed on PubMed Central, the 'PsycINFO' database and CAS, and is the official journal of The International Neuropsychiatric Association (INA). The manuscript management system is completely online and includes a very quick and fair peer-review system, which is all easy to use. Visit http://www.dovepress.com/testimonials.php to read real quotes from published authors. 